\title{
NOVA GESTÃO PÚBLICA E PROGRAMA ‘NAVE-MÃE’: CAMINHOS COMUNS À PRIVATIZAÇÃO
}

\author{
CASSIA DOMICIANO ${ }^{1}$ \\ ORCID: https://orcid.org/0000-0003-3030-2416
}

\begin{abstract}
RESUMO: Neste artigo, analisamos os efeitos da transferência da gestão de Centros de Educação Infantil do setor público para o privado para o atendimento à Educação Infantil pública em CampinasSP. Os aportes financeiros para a sua consecução provinham do governo municipal, por meio da aprovação do Programa de Atendimento Especial à Educação Infantil (PAEEI) no ano de 2007. Focamos a análise nas matrículas públicas e privadas, nos repasses de recursos às instituições privadas e nas características gerais do PAEEI, no período de 2007 a 2014, compreendendo o primeiro ano de vigência do PAEEI, seguindo até o último para o qual os dados estavam disponíveis. Para tal análise, levantamos a legislação ligada ao Programa, as matrículas e os relatórios municipais de acompanhamento e financiamento. Os resultados mostraram que o PAEEI materializou tendências relacionadas à Nova Gestão Pública, abrindo espaço para a constituição de uma "rede" de provedores privados, os quais, além de disputarem a gestão e os recursos públicos, se tornaram atores de destaque na execução da política de Educação Infantil campineira; isso provocou desigualdades no atendimento à criança pequena e direcionou esta etapa da educação básica sob o interesse do setor privado, movimento que denominamos de privatização.
\end{abstract}

Palavras-chave: Privatização, Programa 'Nave-mãe’, Relação Público-Privada, Educação Infantil.

\section{NEW PUBLIC MANAGEMENT AND THE 'NAVE-MÃE' PROGRAM: COMMON WAYS TO PRIVATIZATION}

\begin{abstract}
In this article we analyzed the effects of transferring the management of Early Child Education Centers from the public sector to the private sector in Campinas-SP and its effects for the provision of child education public schools. With the financial support coming from the city government, as sanctioned by the Program for Special Assistance to Early Childhood Education (PAEEI) in 2007, we focused on the analysis of public and private enrollments; the transfer of resources to private institutions and the general characteristics of PAEEI. The study covered the period from 2007 to 2014; from the first year of validity of the PAEEI to the last one for which data was available. We analyzed the legislation related to the Program, schools records and municipal reports for monitoring and financing the Program. The results showed that PAEEI materialized tendencies related to the New Public Management, making way for the constitution of a "network" of private providers, which, in addition to competing for public
\end{abstract}

${ }^{1}$ Professora da Universidade Federal do Paraná. Curitiba, Paraná (PR), Brasil. <cassia.domiciano@ufpr.br> Educação em Revista| Belo Horizonte|v.36|e232177|2020 
management and resources, became prominent players in the enforcement of Early Childhood Education policies in Campinas, leading to inequalities in the care of young children, subordinating this stage of schooling to the interests of the private sector, a movement we call privatization.

Keywords: Privatization, ‘Nave-mãe’ Program, Public-Private Relationship, Childhood Education.

\section{NUEVA GESTIÓN PÚBLICA Y PROGRAMA 'NAVE-MÃE': CAMINOS COMUNES A LA PRIVATIZACIÓN}

RESÚMEN: En este artículo analizamos los efectos, para la asistencia a la educación pública de la primera infancia en Campinas-SP, de la transferencia de la gestión de los centros públicos de educación de la primera infancia (CEI) al sector privado, cuyas contribuciones financieras provenían del gobierno municipal, una condición inaugurada mediante la aprobación del Programa de Asistencia Especial para la Educación de la Primera Infancia (PAEEI) en 2007. Nos centramos en el análisis de las inscripciones públicas y privadas, en la transferencia de recursos a instituciones privadas y en las características generales de PAEEI. El estudio abarcó el periodo de 2007 a 2014, que comprende el primer año de validez del PAEEI, continuando hasta el último para lo cual los datos estuvieron disponibles. Para el análisis, investigamos la legislación relacionada al Programa, las inscripciones y los informes municipales para monitorear y financiar el Programa. Los resultados mostraron que PAEEI materializó tendencias relacionadas a la Nueva Gestión Pública, abriendo espacio para la constitución de una "red" de proveedores privados que, además de competir por la gestión y los recursos públicos, se convirtieron en actores destacados en la ejecución de la política de educación de la primera infancia, en Campinas, generando desigualdades en el cuidado de los niños pequeños y dirigiéndolos desde esta etapa de la escuela bajo el interés del sector privado, un movimiento que llamamos privatización.

Palabras clave: Privatización, Programa 'Nave-mãe, Relación Público-Privada, Educación Infantil.

\section{INTRODUÇÃO}

Este artigo resulta da tese de doutoramento defendida em 2016 na Faculdade de Educação da Unicamp, desenvolvida no âmbito do Grupo de Estudos e Pesquisas em Políticas Educacionais (Greppe), com financiamento da Fundação de Amparo à Pesquisa do Estado de São Paulo (Fapesp). Trata-se de um recorte da investigação que tem como foco a análise dos efeitos para o atendimento à Educação Infantil pública a partir da transferência da gestão de equipamentos educacionais ao setor privado com aporte de verbas públicas, inaugurada no município paulista de Campinas a partir da sanção do Programa de Atendimento Especial à Educação Infantil (PAEEI), em 2007.

A delimitação temporal abrangeu o primeiro ano de implementação do PAEEI, marcado pela aprovação da Lei Municipal no 12.884 em abril de 2007, seguindo até 2014, último ano para o qual dispúnhamos de dados publicados. Evidenciamos, neste trabalho, que a transferência da gestão de unidades públicas a instituições de caráter privado, subsidiadas com recursos públicos, alterou de forma significativa o cenário da oferta, da gestão e do financiamento da Educação Infantil em Campinas, assim como inseriu esta etapa da educação básica em uma lógica privatizante e mercadológica que se relaciona às tendências da Nova Gestão Pública. 
Para a apreensão do objeto estudado, empregamos a pesquisa documental recorrendo a fontes primárias de documentos. A opção por este procedimento e pelo instrumento de análise se deve ao fato de serem uma rica fonte de dados que conserva registros do período analisado, tal como foram elaborados (GODOY, 1995). Além disso, os documentos retratam, de maneira explícita, ou implícita, as concepções e opções políticas da administração pública da época.

As informações relacionadas ao cenário da oferta foram buscadas junto ao portal do Instituto Nacional de Estudos e Pesquisas Educacionais Anísio Teixeira (Inep) e corresponderam às matrículas públicas e privadas de creche e pré-escola. Utilizamos, ainda, matrículas contabilizadas pelo Setor de Convênios e Núcleo de Educação Infantil da Secretaria Municipal de Campinas, disponibilizadas por meio de planilhas próprias. Tais dados nos permitiram conhecer de forma detalhada a quantidade de crianças atendidas pelo PAEEI e pelas demais instituições privadas conveniadas, elementos que não captávamos pelo Inep.

Quanto aos dados referentes ao Programa e à organização do sistema de ensino, estes foram encontrados nos documentos oficiais de criação e regulamentação. Sobre o PAEEI, utilizamos a lei 12.884/2007, os decretos 15.947/2007 e 17.523/2012 e o Guia Gestor (2013); quanto àqueles relativos ao sistema, usamos o decreto $\mathrm{n}^{\circ} 11.051 / 1992$ e o de $\mathrm{n}^{\mathrm{o}} 17.951 / 2013$. Acessamos toda a legislação consultada na biblioteca jurídica on-line e conseguimos a versão impressa do Guia Gestor após pedido protocolado na SME.

Com a finalidade de mostrar a apropriação de recursos públicos por parte das entidades que geriam os equipamentos educacionais, utilizamos um relatório emitido pela Administração e Gerenciamento de Convênios da SME, no qual constavam: nome das entidades privadas que geriam os CEI, período de vigência com a Secretaria Municipal de Educação, total de crianças atendidas e valores despendidos na série histórica da pesquisa. Desse modo, por meio do documento, identificamos o valor dos gastos especificamente direcionados às entidades privadas para operacionalizar a gestão dos CEI 'Naves-mãe', montantes que não apareciam desagregados na Execução Orçamentária Municipal.

Os dados sobre as Associações Privadas (AP), responsáveis pela administração dos CEI públicos, foram obtidos junto ao sítio da Receita Federal Brasileira, por meio do relatório financeiro entregue pela SME e pelos estatutos e documentos que retratavam o histórico educacional de tais associações, também disponibilizados em documentos impressos, após mediação e exigência da SME. Para garantir o anonimato exigido pelas entidades, identificamo-las no texto sob a sigla AP, seguidas pelos algarismos arábicos de 1 a 9, dispostas em ordem crescente de formalização do convênio com a SME.

De acordo com o que dissertam Gomide e Jacomeli (2016), as políticas educacionais não se isolam da totalidade social e, neste movimento da totalidade, está um conjunto amplo de relações, particularidades e detalhes marcados por interesses econômicos, políticos e ideológicos, impossibilitando "[...] captar o significado de uma política educacional sem compreender a lógica global do sistema orgânico do capital” (GOMIDE; JACOMELI, 2016, p. 72) e sem considerar as contradições geradas pela implementação dessas políticas no marco do capitalismo.

À vista disso, buscamos captar o movimento do PAEEI nesta totalidade por meio do percurso metodológico apresentado, com aporte teórico de autores que trataram do tema da Nova Gestão Pública brasileira - Garcia, Adrião e Borghi (2009) e Junquilho (2002) -, das conformações do Estado no pós-guerra - Harvey (2005, 2009), Hobsbawn (1995), Peroni e Adrião (2005) e Peroni (2013) -, da trajetória histórica da educação infantil - Campos (1989), Correa (2007), Faria (1999, 2005), Kramer (1995), Kuhlmann (2000, 2004), Rosemberg (1999, 2007) -, da privatização da educação - Adrião (2009, 2014), Adrião e Bezerra (2013), Adrião e Peroni (2013); Oliveira e Borghi (2013); Domiciano-Pellisson (2016); Domiciano (2017); Belfield e Levin (2002) - e, ainda, daqueles que estudaram o PAEEI sob diferentes perspectivas, como Ceccon (2018), Momma-Bardella, Palmen e Bryan (2014), Rocha (2009) e Silva (2016). 
Desse modo, organizamos o artigo em oito seções: a primeira composta por esta introdução; a segunda, pela contextualização e características gerais da Nova Gestão Pública; na terceira, apresentamos a histórica relação público-privada na Educação Infantil brasileira. Na quarta seção, trazemos informações acerca da população campineira, com foco na faixa etária correspondente à creche e pré-escola, somadas àquelas relacionadas ao PAEEI; na quinta, estão as análises das adequações legais da política local ao PAEEI e do cenário da oferta da Educação Infantil em que percebemos o avanço das entidades privadas; na sexta, discutimos algumas percepções circunscritas à relação público-privada provenientes do PAEEI; na penúltima seção, apresentamos os montantes despendidos às Associações Privadas para gestão dos equipamentos públicos; e, nas considerações finais, explicitamos as contradições do Programa e seu caráter privatizante.

\section{NOVA GESTÃO PÚBLICA (NGP): CONTEXTO HISTÓRICO E CARACTERÍSTICAS}

Autores como Garcia, Adrião, Borghi (2009) e Junquilho (2002, 2004) caracterizam a Nova Gestão Pública (NGP), New Public Manegement (NPM) ou Gerencialismo como um movimento de reforma dos Estados Nacionais, iniciado em diferentes países de capitalismo desenvolvido - Inglaterra, Estados Unidos, Alemanha, Bélgica - nas últimas décadas do século XX, em resposta à crise econômica dos anos de 1970.

O modelo de estado-nação que vigorou naqueles países até o início dos anos de 1970 fomentou, instituiu e financiou políticas de bem-estar social e regulou a economia. Ao longo do período pós-guerra (1945), o crescimento econômico dos países capitalistas tornou-se forte e relativamente estável, os padrões de vida elevaram-se, e as tendências de crises do capital se reduziram. Naquele momento, o Estado assumiu o papel de controlar os ciclos econômicos combinando políticas fiscais e econômicas, além de regular direta ou indiretamente os acordos salariais e os direitos dos trabalhadores na produção (HARVEY, 2009; HOBSBAWN, 1995).

Criação do capitalismo no período do pós-guerra, o Welfare State caracterizou-se por uma rede de proteção social constituída pelo investimento do Estado na implantação de serviços sociais estatais, como educação pública, saúde pública, habitação, previdência social. Para Harvey,

Esse contexto 'keynesiano' dos gastos do Estado era coerente com uma dinâmica de luta de classes no interior de nações-Estados individuais com respeito a questões distributivas. Essa foi uma época em que o trabalho organizado se tornou bem forte e surgiram em toda Europa Estados socialdemocratas de bem-estar social (HARVEY, 2005, p. 54).

Em vista disso, nos países de economia avançada, aquela foi a "era de ouro" para a expansão do capital e o acesso aos bens e serviços públicos por grande parte da população (HOBSBAWN, 1995). Entretanto, o acesso vivenciado em épocas de "capitalismo democrático" duraria até meados de 1973, embora em 1965 já apresentasse sinais de que tempos difíceis se avizinhavam.

De modo mais geral, afirma Harvey (2009), o período de 1965 a 1973 evidenciou a incapacidade do fordismo e do keynesianismo de conter as contradições inerentes do modo de produção capitalista, que, mais uma vez, viu sua capacidade de lucro estagnar em função de uma rigidez nas formas econômicas e políticas do modelo de acumulação keynesiano.

Havia problemas com a rigidez dos investimentos de capital fixo de larga escala e de longo prazo em sistemas de produção em massa que impediam muita flexibilidade de planejamento e presumiam crescimento estável em mercados de consumo invariantes. Havia problemas de rigidez nos mercados, na alocação e nos contratos de trabalho (HARVEY, 2009, p. 135).

A partir da estagnação econômica iniciada na segunda metade do século XX, que culminou em uma crise estrutural do sistema capitalista, adeptos de orientações políticas neoliberais e outras correntes de mesma matriz ideológica, como a Terceira Via e a Teoria da Escolha Pública, creditaram a responsabilidade desse desequilíbrio à conformação estatal do período (PERONI; ADRIÃO, 2005).

Para aqueles que identificavam a origem da crise no Estado e não no capital, a estratégia para superação seria ampliar a ação do mercado e diminuir a intervenção estatal na economia e na oferta direta 
dos serviços sociais (PEREIRA, 1998). Além disso, a burocracia estatal, símbolo de ineficiência, deveria pautar-se pelos princípios de gestão empresarial, mais eficiente e produtiva.

Recorrendo a um consentimento político, construído por meio de diferentes canais e com forte apelo ideológico, propostas reformadoras proliferaram-se por diferentes países, sem que se tivesse um modelo único (HARVEY, 2005). As variações acompanharam o grau de desenvolvimento econômico, estrutural e organizativo de cada país e a maneira como cada estado-nação absorveu as indicações neoliberais e da Terceira Via (JUNQUILHO, 2002).

Embora não existisse um modelo único de reforma, características comuns marcaram a Nova Gestão Pública, estando presentes tanto em países que não desmontaram totalmente o Estado de Bem-Estar Social quanto naqueles que não o construíram efetivamente, como é o caso do Brasil. Com base em estudos de Junquilho (2002), assinalamos a sistematização dessas características e orientações, identificando que:

- O gasto público é um custo improdutivo, perdendo o sentido de investimento coletivo e social;

- Os servidores públicos são identificados como detentores de privilégios e defensores de interesses particulares;

- A interferência do Estado no mercado impede o avanço econômico;

- O mercado é um "ser" supremo, considerado mais eficiente para distribuir os bens à sociedade;

- O Estado deve ser empreendedor, característica que suprime sua condição de provedor de bens e serviços sociais;

- Devem-se incorporar no Estado práticas gerenciais (eficiência, eficácia, produtividade, avaliação e controle de resultados);

- O papel dos administradores públicos deve ser o mesmo que o dos gerentes empresariais: tornarem-se gestores públicos profissionalizados (empreendedores);

- A privatização de setores econômicos produtivos estatais é necessária;

- A desregulação dos mercados comerciais e de trabalho como parte da agenda de crescimento.

Assim sendo, tais características e orientações se inter-relacionam e se complementam, coerentes ao tipo de Estado, sociedade e desregulação econômica que se defende para superação da crise econômica.

No Brasil, o Plano Diretor de Reforma do Aparelho do Estado (PDRAE), defendido e elaborado por Luís Carlos Bresser Pereira na primeira gestão do governo de Fernando Henrique Cardoso (19951998), incorporou boa parte do ideário da NGP. O PDRAE constitui-se no Plano de Partida para a elaboração e aprovação de um arcabouço legal que privilegiou a ação do setor privado para garantia de serviços sociais (PERONI; ADRIÃO, 2005; PERONI; OLIVEIRA; FERNANDES, 2009).

$\mathrm{Na}$ perspectiva de autores como Adrião (2009) e Adrião e Bezerra (2013), as reformas brasileiras diferenciaram-se das consolidadas em outros países, como Inglaterra e Chile, onde ocorreram transferências de propriedades públicas ao setor privado ou, ainda, a redução do gasto público com educação ${ }^{2}$. Isso porque o período de construção e elaboração das orientações para reforma da gestão pública brasileira coincidiu com as críticas aos efeitos das proposições neoliberais, implementadas pioneiramente na Inglaterra e Estados Unidos, e "mesmo os adeptos do mais mercado e menos Estado buscavam outras alternativas" (ADRIÃO, 2009, p. 51).

As estratégias previstas e colocadas em andamento no Brasil ao fim dos anos de 1990 aproximavam-se do que propunha a Terceira Via, que correspondia à participação de novos atores na oferta e manutenção das políticas sociais "em parceria com instituições da sociedade civil para fomentar a renovação e o desenvolvimento da comunidade" (GIDDENS, 2005, p. 87).

Tornou-se, então, cada vez mais frequente a formalização de pactos de atuação conjunta entre governo e setor privado que primavam pela lógica gerencial da esfera privada na administração pública, na "perspectiva de consolidar um sentido de corresponsabilização da 'sociedade civil' no que diz respeito à garantia e à ampliação do acesso aos direitos sociais básicos” (ADRIÃO; BEZERRA, 2013, p. 258).

${ }^{2} \mathrm{~A}$ conjuntura pós-eleições de 2018 delineia outros cenários para o Brasil. Tal diagnóstico tem se alterado à medida que o atual chefe de Estado, Jair Bolsonaro, e seus ministros, anunciam listas de privatizações (SANT'ANA, 2019), atacam as Universidades Públicas com falsas acusações e cortam recursos públicos (OLIVEIRA, 2019). 
A percepção de que a solução para os problemas da Administração Pública estaria na adoção de medidas elaboradas pelo setor privado ou de sua inserção como "colaborador" dos governos nas diferentes esferas da federação "assume status de opções de políticas regulamentadas a partir da Emenda Constitucional $\mathrm{n}^{\circ} 19$ de 1988 (EC-19/98), pela qual se introduziram profundas alterações na administração pública" (ADRIÃO; BEZERRA, 2013, p. 258).

Desse modo, a EC-19/1998

[...] implementou modificações no regime administrativo brasileiro, a partir da alteração de um grande número de dispositivos da Constituição Federal de 1988, referente tanto ao funcionamento da administração pública, quanto às normas até então vigentes para os seus servidores (ADRIÃO; BEZERRA, 2013, p. 258).

Das alterações trazidas pela EC-19/1998, três estão relacionadas diretamente ao objeto de estudo deste trabalho: 1) a introdução do princípio da eficiência; 2) a retirada da exigência de uma legislação específica para criação das entidades paraestatais ${ }^{3}$; e 3) a introdução do Contrato de Gestão.

Quanto ao primeiro caso, embora exista um precedente indissociável da gestão pública à formalização legal da exigência do exercício eficiente dos serviços públicos, induziu-se à introdução de modelos de gestão baseados na administração privada, dadas as bases ideológicas nas quais se assentou a reforma gerencial do Estado.

No segundo, a nova regulamentação das instituições paraestatais "facilitou a generalização de entidades de natureza mista, reconfigurando a gestão da administração pública" (ADRIÃO; BEZERRA, 2013, p. 259), bem como facilitou e legitimou o acesso aos recursos públicos por parte destas instituições. Por fim, a introdução do Contrato de Gestão formalizou a ideia do público não-estatal ao permitir a operacionalização de serviços sociais por Organizações Sociais, atenuando e/ou diluindo as fronteiras entre o público e o privado (BAUER, 2008).

Neste contexto, os mecanismos citados permitiram a flexibilização das relações entre a iniciativa privada e o Poder Público, fomentando a criação de múltiplos acordos. Aprofundaram, também, a privatização dos serviços sociais em âmbito nacional e local.

A privatização é aqui entendida pelas perspectivas de Belfield e Levin (2002) e Adrião (2018), que a consideram um processo de transferência de responsabilidades, equipamentos, estruturas, currículo etc. para o setor privado ou, ainda, a transferência da responsabilidade sobre a garantia de determinada política para o setor privado ou atores privados.

Para contribuir com o debate sobre o aprofundamento da privatização, no âmbito da educação básica pública brasileira, apresentamos a análise da transferência da gestão de equipamentos públicos educacionais a entidades privadas, subsidiada com recursos públicos, formalizada por meio do Programa de Atendimento Especial à Educação Infantil (PAEEI) e implementado em Campinas-SP, em 2007. Antes, porém, contextualizamos brevemente a histórica relação público-privada na educação infantil brasileira, cujos aportes de recursos públicos favoreceram sua ampliação pela via do conveniamento.

\section{A HISTÓRICA RELAÇÃo PÚBLICO-PRIVADA NA EDUCAÇÃO INFANTIL BRASILEIRA}

A busca inicial pela assistência, proteção e educação à infância, no Brasil, ligava-se originalmente aos cuidados às crianças pobres, expostas a doenças e precárias condições de sobrevivência; tanto é que os médicos foram os primeiros a voltarem suas atividades profissionais e políticas à educação, tornando-se donos de escolas, pesquisadores e membros de órgãos governamentais e associações direcionadas à educação popular. Esta influência médico-higienista, iniciada na década de 1870 e aprofundada em 1874, exerceria papel predominante nas discussões sobre a criança no Brasil (CAMPOS, 1989; FARIA, 2005; KRAMER, 1995; KUHLMANN, 1998; ROSEMBERG, 1999).

\footnotetext{
${ }^{3}$ As entidades paraestatais incluem os Serviços Sociais Autônomos (Sesi, Senai, Sesc, Sebrae), as entidades de apoio (Fundações, Associações e Cooperativas), as Organizações Sociais (OS) e as Organizações da Sociedade Civil de Interesse Público (Oscips) e demais Organizações da Sociedade Civil (OSC) (ADRIÃO; BEZERRA, 2013).
} 
Nesse sentido, tomando a sistematização de Kramer (1995) como base, dividimos o histórico da proteção à infância no Brasil em três períodos: o primeiro, do descobrimento até 1874, em que pouco ou quase nada se fazia pela 'infância desditosa', tanto relativamente à proteção jurídica, quanto às alternativas de atendimento existentes. O segundo momento, que engloba os anos de 1874 até 1889 , período que "se caracterizaria, sobretudo, pela existência de projetos elaborados por grupos particulares [que não se concretizavam], em especial médicos, que tratavam do atendimento a crianças" (KRAMER, 1995, p. 48); e, por fim, o terceiro, de 1890 a 1930, marcado pelo progresso no campo da higiene infantil, médica e escolar.

No último período, ou até meados de 1920, a assistência à infância efetivou-se por meio de instituições particulares que eram, em sua maioria, de caráter caritativo e filantrópico, com a direção e alguma subvenção do governo (KRAMER, 1995).

A década de 1930 foi marcada por transformações políticas e econômicas, como a substituição da monocultura latifundiária pelas importações - opção decorrente da crise cafeeira provocada pela recessão mundial de 1929 -, o fortalecimento de novos grupos econômicos (surgimento da nova burguesia urbano-industrial), a mudança na estrutura da sociedade brasileira com o crescimento do setor industrial, a ampliação da classe média, a urbanização, o aparecimento de um proletariado industrial e a Revolução de 1930 que apresentou, primeiramente, seus traços centralizadores e, posteriormente, ditatoriais (Estado Novo) (KRAMER, 1995). Assim, tais transformações influenciariam, gradativamente, as políticas para educação infantil e ampliariam as pressões populares pelo acesso à creche e pré-escola.

Naquele período, embora o poder público fosse cada vez mais chamado a regulamentar o atendimento das crianças pequenas, ele o fazia de forma tímida e convocava indivíduos isolados e associações particulares a colaborarem financeiramente com as instituições destinadas à proteção das crianças (KRAMER, 1995).

$\mathrm{Na}$ tentativa de formalizar a regulação da educação, o Estado criou, em 1930, o Ministério da Educação e da Saúde Pública, que contava com o Conselho Nacional de Educação como órgão consultivo nos assuntos técnicos e didáticos relacionados ao ensino e à Ação ou Assistência MédicoSanitária. Duas tendências predominavam nesse Ministério: a primeira, voltada ao combate à mortalidade infantil por meio de orientações médicas ligadas aos cuidados com a higiene e a saúde das crianças; a segunda, vinculada ao exercício da caridade aos pobres e necessitados (KRAMER, 1995; KUHLMANN, 2000).

Destoando das tendências médico-higienistas, temos a criação dos Parques Infantis no município de São Paulo em 1935, com atendimento às crianças menores de sete anos, idealizada por Mário de Andrade, então diretor do Departamento de Cultura. Para Faria (1999), tal experiência foi a primeira prática municipal pública, embora não escolar, que contemplou crianças originárias de famílias operárias.

No âmbito federal, mantinha-se a oferta por meio da Assistência Social, tendo como principal ator a Legião Brasileira de Assistência (LBA), criada em 1942 e transformada em Fundação em 1969. Conforme Rosemberg (1999), a LBA ampliou rapidamente o atendimento à criança pequena no fim dos anos de 1970, a partir do Projeto Casulo. Atuando de forma indireta, mediando o repasse de recursos para instituições privadas e prefeituras, a LBA implantou, antes do MEC, um programa nacional de expansão de vagas a baixo custo (ROSEMBERG, 1999).

Para responder às pressões populares de um lado e ampliar o atendimento às crianças de outro, somava-se, às ações da LBA, o incentivo governamental às creches comunitárias, iniciativas da comunidade há muito existentes. Belo Horizonte, caso exemplar a esse respeito, foi um lugar em que as subvenções públicas criaram ambiguidades no próprio movimento que lutava pela expansão do atendimento à infância: exigir uma política de creches públicas e gratuitas geridas pelo Estado, ou defender a manutenção de uma política de subvenção às creches comunitárias e o seu controle pela população? (FILGUEIRAS, 1994).

A resposta para os envolvidos no movimento à época não era simples nem fácil de se formular, tendo em vista que, contraditoriamente, era pleiteada a ruptura do assistencialismo na área e reivindicada a participação do Estado na oferta da Educação Infantil. No entanto, a precariedade das condições de vida da população e o reduzido número de crianças atendidas fizeram com que o 
movimento defendesse os dois tipos de estratégias: a busca pela ampliação do atendimento público e a manutenção e subvenção pública às creches comunitárias (FILGUEIRAS, 1994).

Campos (1989) apresenta outro dado considerável que catalisou a ampliação do atendimento aos pequenos via convênio com instituições assistenciais filantrópicas e/ou comunitárias. A autora lembra que, além do baixo custo da expansão mediante entidades, sua adesão aos convênios se dava em razão das vantagens financeiras que poderiam obter.

A trajetória política da Educação Infantil ganhou contornos legais, especificamente de Direito, a partir da aprovação da Constituição Federal de 1988, condição reafirmada posteriormente pelo Estatuto da Criança e do Adolescente (lei no 8.069/1990) e pela Lei de Diretrizes e Bases da Educação Nacional (lei no 9.394/1996).

Mesmo com todos os avanços relacionados à área da infância, seja na produção do conhecimento, na constitucionalização do direito, na luta pela ampliação do acesso ou no crescimento da oferta pública (BORGHI, 2012; OLIVEIRA; BORGHI, 2013; ROSEMBERG, 2007), as políticas educacionais reeditam normas que permitem o acesso a recursos públicos por instituições privadas, mantendo e aprofundando o histórico processo de privatização da Educação Infantil, em especial da etapa de creche.

Um exemplo dessa prática reiterada está na regulamentação do Fundo de Manutenção e Desenvolvimento da Educação Básica (Fundeb), pela lei 11.494, de 20 de junho de 2007, ao permitir o repasse dos recursos do fundo às instituições conveniadas de caráter comunitário, filantrópico ou confessional. Ainda que se considere o avanço do Fundeb em relação ao fundo anterior (Fundef), por abarcar toda matrícula da educação básica, concordamos com Pinto (2007, p. 888) ao afirmar que se tratou de um "duro golpe no princípio de que recursos públicos devem se destinar às instituições públicas". Outro exemplo de destaque encontramos no texto do Plano Nacional de Educação (lei 13.005/2014 - 2014-2024), que mantém a ideia de expansão da creche por meio de entidades beneficentes de assistência social ${ }^{4}$, evidenciando que o status de Direito, constitucionalizado há mais de trinta anos, não foi capaz de alcançar seu real lugar, tampouco de mudar os paradigmas históricos desta etapa da educação básica.

\section{O PROGRAMA DE ATENDIMENTO ESPECIAL À EDUCAÇÃO INFANTIL (PAEEI) NO MUNICÍPIO DE CAMPINAS-SP}

Campinas localiza-se no interior do estado de São Paulo a uma distância de aproximadamente cem quilômetros da capital. Pela Projeção Populacional divulgada pelo Sistema Estadual de Análise de Dados (Seade), o número estimado de habitantes, em 2014, era de 1.123.241. Desse total, 57.386 eram crianças na faixa etária de 0 a 3 anos; e 26.279, de 4 a 5 anos (SEADE, 2014). A taxa de escolarização líquida ${ }^{5}$ desses grupos etários correspondia, naquele ano, a respectivamente 37,90\% e 99,92\% (DOMICIANO-PELLISSON, 2016), explicitando o maior déficit na etapa de creche.

No intervalo delimitado para análise (2007-2014), esteve à frente do executivo municipal Hélio de Oliveira Santos, conhecido como Dr. Hélio, do Partido Democrático Trabalhista (PDT) (20052008 e 2009-2011). Reeleito em 2009, teve o mandato cassado ${ }^{6}$ em 2011. Ainda em seu primeiro mandato, Dr. Hélio apresentou ao juiz da Vara da Infância e da Juventude do município, Richard Pae Kim, um projeto que previa a edificação de Centros de Educação Infantil que teriam, cada um, capacidade para atender até 500 crianças na faixa etária de 4 meses a 5 anos e 11 meses (SANTOS, 2010). O projeto fez parte de um plano de resposta ao Ministério Público, pois Campinas, como boa parte dos municípios brasileiros, acumulava inquéritos para apurar a falta de vagas na Educação Infantil, que datavam de 1997 (ROCHA, 2009).

\footnotetext{
${ }^{4}$ Meta 1, estratégia 1.7.

${ }^{5} \mathrm{~A}$ taxa de matrícula líquida é a proporção entre os matriculados em determinado nível/etapa da educação básica em relação à população na faixa etária adequada a esse nível/etapa da educação básica (OLIVEIRA, 2007).

${ }^{6} \mathrm{O}$ então prefeito de Campinas ocupava o segundo mandato do executivo municipal. Manteve-se no cargo até agosto de 2011 , sendo cassado pela Câmara dos vereadores em virtude de um impeachment. Hélio de Oliveira Santos foi acusado de infrações político-administrativas (ENTENDA, 2014).
} 
A averiguação pautava-se nas denúncias do Conselho Tutelar Municipal, que indicava o descumprimento do artigo $54^{7}$ do Estatuto da Criança e do Adolescente (DOMICIANO-PELLISSON, 2016; DOMICIANO, 2017). O plano de resposta ao MP materializou-se no Projeto de Lei $n^{\circ} 133 / 2007$, registrado pelo então prefeito e apresentado diretamente por ele ao plenário da Câmara municipal, em 12 de março de 2007. Sem contemplar audiências públicas ou quaisquer discussões com os segmentos educacionais, após duas sessões de debates e votação, os vereadores aprovaram o PL, posteriormente sancionado pelo executivo (DOMICIANO-PELLISSON, 2016).

De tal PL, originou-se a Lei Municipal no 12.884, sancionada em 4 de abril de 2007. A partir dela, instituiu-se o Programa de Atendimento Especial à Educação Infantil (PAEEI), popularmente conhecido como Programa 'Nave-mãe'. O PAEEI passou efetivamente a funcionar no ano de 2008. Regulamentado pelo decreto $\mathrm{n}^{\circ} 15.947^{8}$, em 17 de agosto daquele ano, o ordenamento legal permitiu "a criação de Centros de Educação Infantil (CEI), unidades de Educação Infantil da Secretaria Municipal de Educação (SME)" (CAMPINAS, 2007), com gestão realizada por instituições de direito privado sem fins lucrativos. Desse modo, os CEI que integraram o PAEEI receberam o nome de 'Naves-mãe".

Em sua configuração inicial ${ }^{10}$, os prédios das 'Naves-mãe' tinham aproximadamente 1.800 metros quadrados de área coberta e seguiam o mesmo padrão arquitetônico que resultou do projeto elaborado por João Filgueiras Lima" (SANTOS, 2010). Por apresentarem um "desenho" diferenciado das demais unidades da rede municipal, as 'Naves-mãe' eram facilmente identificadas pelo "perfil arquitetônico", constituindo-se a "marca" do Programa implementado (DOMICIANO-PELLISSON, 2016; DOMICIANO, 2012, 2017).

Construídos, equipados e mantidos com recursos públicos, os CEI 'Naves-mãe' tinham e têm sua gestão transferida a instituições privadas sem fins lucrativos, selecionadas conforme exigências técnicas e jurídicas publicadas em edital de processo seletivo público. Para gerir as 'Naves-mãe', o governo municipal repassava trimestralmente um montante de público às entidades, calculado com base no número de crianças matriculadas. Os valores diferenciavam-se conforme a faixa etária atendida, sendo maiores para a etapa de creche (DOMICIANO-PELLISSON, 2016; DOMICIANO, 2012, 2017).

Ao longo do período de nossa investigação (2007-2014), a municipalidade construiu e transferiu a gestão de 16 Centros de Educação Infantil 'Naves-mãe' para o setor privado. Estendendo o intervalo até 2015 , temos oito novos equipamentos inaugurados, totalizando $24^{12}$ unidades geridas por instituições privadas (CECCON, 2018). Tal opção política para expansão de vagas mudou radicalmente o cenário da oferta e da gestão educacional em Campinas.

\section{ADEQUAÇÕES LEGAIS NA POLÍTICA EDUCACIONAL LOCAL E O CENÁRIO DA OFERTA NA EDUCAÇÃO INFANTIL}

Até 2013, a rede municipal campineira ofertava a Educação Infantil em equipamentos públicos denominados Centros Municipais de Educação Infantil (Cemeis), que atendiam crianças de 4 meses a 5 anos e 11 meses, em turno integral e, em Escolas Municipais de Educação Infantil (Emeis), responsáveis pela faixa etária de 4 a 5 anos e 11 meses, em turno parcial. O decreto $\mathrm{n}^{\circ} 17.951^{13}$, de 2 de

\footnotetext{
${ }^{7}$ Art. 54. É dever do Estado assegurar à criança e ao adolescente: IV - atendimento em creche e pré-escola às crianças de zero a seis anos de idade.

${ }^{8}$ Alterado pelo Decreto n ${ }^{\circ} 17.523$, de 27 de fevereiro de 2012.

${ }^{9} \mathrm{O}$ levantamento documental não permitiu identificar a origem do nome 'Nave-mãe'. Pesquisa recente de Ceccon (2018) mostra que o atual prefeito, Jonas Donizete, denomina os CEIs 'Naves-mãe' de 'Bem-querer'. Para a autora, isso significou uma tentativa do executivo de se desvencilhar do nome do Programa dado pela gestão anterior, bem como demarcar sua autoria.

${ }^{10}$ Ao longo da vigência do Programa, a arquitetura foi-se alterando para atender às exigências de construção do Programa PróInfância do governo federal (DOMICIANO-PELLISSON, 2016).

${ }^{11}$ Arquiteto, urbanista e construtor, conviveu com Oscar Niemeyer, o qual exerceu muita influência em suas produções. Disponível em: <http://enciclopedia.itaucultural.org.br/pessoAP18200/joao-filgueiras-lima>. Acesso em: 10 ago. 2015. Conforme Santos (2010), o convite a Lelé deveu-se à experiência educacional em ações como os Centros Integrados de Educação Pública (CIEPs) implementados no governo de Leonel Brizola, no Rio de Janeiro.

${ }^{12}$ Dados disponíveis no site oficial de Campinas (<http://integre-master.ima.sp.gov.br/integre/web/cons_escola_list.php>) - mostram 29 equipamentos públicos (Naves-mãe) com gestão privada no ano de 2020.

${ }^{13}$ Ver alteração decorrente no Decreto no 18.664 , de 03 de março de 2015.
} 
maio de 2013, agrupou, sob a mesma nomenclatura, todas as instituições públicas, nomeando-as como Centro de Educação Infantil (CEI), conforme descrito no Quadro 1.

Quadro 1 - Alteração na nomenclatura das Unidades Municipais de Educação Infantil de Campinas.

\begin{tabular}{|l|l|}
\hline \multicolumn{1}{|c|}{ Até 2012 - Decreto $\mathbf{n}^{\mathbf{0}} \mathbf{1 1 . 0 5 1 / 1 9 9 2}$} & A partir de 2013 - Decreto $\mathbf{n}^{\mathbf{0}} \mathbf{1 7 . 9 5 1 / 2 0 1 3}$ \\
\hline $\begin{array}{l}\text { Centro Municipal de Educação Infantil } \\
\text { (Cemei) - Funcionavam no mesmo } \\
\text { equipamento a etapa de creche e pré-escola - } \\
4 \text { meses a } 5 \text { anos e } 11 \text { meses. }\end{array}$ & $\begin{array}{l}\text { Centros de Educação Infantil - } \\
\text { mantiveram o atendimento à faixa etária de } 4 \\
\text { meses a } 5 \text { anos e 11 meses. }\end{array}$ \\
\hline $\begin{array}{l}\text { Escola Municipal de Educação Infantil } \\
\text { Emei)- Atendia à etapa de pré-escola - } 4 \text { a } \\
5 \text { anos e 11 meses. }\end{array}$ & $\begin{array}{l}\text { Centros de Educação Infantil - atendiam à } \\
\text { mesma faixa etária, com adequações na } \\
\text { organização etária dos agrupamentos para } \\
\text { atendimento à demanda. }\end{array}$ \\
\hline
\end{tabular}

Fonte: Sistematizado pela autora com base nos decretos no 11.051/1992 e no 17.951/2013.

Apesar de estarem sob a mesma terminologia, notam-se diferenças entre um CEI 'Navemãe', criado pelo PAEEI, e um CEI da rede direta, relacionadas tanto à faixa etária de crianças atendidas, quanto ao responsável pela gestão dos equipamentos. Considerando o levantamento documental (legislação, relatórios do Programa), caracterizamos os CEI da seguinte maneira:

Centros de Educação Infantil Municipais (CEI): unidades de Educação Infantil da rede direta, construídas, mantidas e geridas pelo poder público. No ano de 2014, 69 CEI atendiam à faixa etária de 4 meses a 5 anos e 11 meses; e 69, à etapa de pré-escola - crianças de 4 a 5 anos (CAMPINAS, 2015). O ingresso de professores e gestores efetivava-se por meio de concurso de provas e títulos, com progressão prevista em Plano de Carreira e remuneração mantida pelo executivo municipal.

Centros de Educação Infantil (CEI) 'Naves-mãe': unidades de Educação Infantil com o mesmo padrão arquitetônico, construídas e mantidas pelo poder público e de gestão privada. Atendiam crianças na faixa etária de 4 meses a 5 anos e 11 meses. As entidades que administravam os CEI eram selecionadas por seus Planos de Trabalho mediante edital de processo seletivo público. As aprovadas recebiam subsídio per capita para gestão das unidades, kits de uniformes escolares e merenda. O ingresso de docentes e gestores efetivava-se por meio de processo seletivo realizado pelas entidades gestoras, os profissionais não acessavam Plano de Carreira Municipal e tinham seus salários mantidos pelo per capita repassado à instituição.

Outro ator presente na configuração da rede educacional de Campinas e, historicamente, no Brasil eram as Entidades Conveniadas, instituições privadas, sem fins lucrativos, que recebiam subsídio público para ofertarem vagas às crianças na etapa de creche e pré-escola. As entidades não participavam de chamamento público, tampouco passavam por processo seletivo. Além do subsídio per capita, recebiam merenda escolar. As regras de conveniamento e valores per capita diferenciavam-se dos estabelecidos às 'Naves-mãe'.

No período da pesquisa, o número de unidades de Educação Infantil em cada um desses segmentos correspondia ao disposto na Tabela 1.

Tabela 1 - Número de unidades de Educação Infantil por tipo de estabelecimento Campinas (20082014).

\begin{tabular}{l|c|c|c|c|c|c|c}
\hline CEI Infantis & $\mathbf{2 0 0 8}$ & $\mathbf{2 0 0 9}$ & $\mathbf{2 0 1 0}$ & $\mathbf{2 0 1 1}$ & $\mathbf{2 0 1 2}$ & $\mathbf{2 0 1 3}$ & $\mathbf{2 0 1 4}$ \\
\hline CEI diretos & 140 & 142 & 141 & 141 & 140 & 139 & 138 \\
CEI 'Nave' & 4 & 8 & 12 & 14 & 16 & 16 & 16 \\
Conveniadas & 39 & 40 & 39 & 41 & 42 & 42 & 42 \\
\hline Total & $\mathbf{1 4 4}$ & $\mathbf{1 5 1}$ & $\mathbf{1 5 4}$ & $\mathbf{1 5 4}$ & $\mathbf{1 5 6}$ & $\mathbf{1 5 5}$ & $\mathbf{1 5 4}$ \\
\hline
\end{tabular}

Fonte: Sistematizado pela autora com base no relatório "Dados de matrícula e equipamentos escolares" (2008-2014), disponibilizado pela Secretaria Municipal de Educação. 
Notamos pela tabela que, em 2014, a rede direta totalizava 138 CEI, dois a menos do que em 2008; entretanto, o número de 'Naves-mãe' quadriplicou no mesmo intervalo. Além disso, as entidades conveniadas também se ampliaram, somando 42 instituições. Ainda que em maior quantidade, não podemos dizer que a oferta de vagas pela rede direta era superior, pois as matrículas decresceram ao longo dos anos investigados, enquanto a somatória de matrículas das "Naves", conveniadas e privadas stricto sensu', aumentou. A Tabela 2 e as Figuras 1 e 2 ilustram esse movimento.

Antes da análise das matrículas, explicitamos que a composição dos números da rede pública e privada stricto sensu se deu pelos dados do Inep. Já os dados referentes às 'Naves-mãe' e conveniadas, nós os sistematizamos por meio de informações disponibilizadas pela Secretaria Municipal de Educação (Setor de Convênios e Núcleo de Educação Infantil), uma vez que, pelo Inep, o nível de desagregação não chegava às 'Naves-mãe', pois a estas se somavam as matrículas públicas. Como já discutido em outro momento (DOMICIANO, 2009, 2012; DOMICIANO-PELLISSON, 2016), a prática das prefeituras de registrarem o número de vagas privadas conveniadas na rede pública, sejam elas de gestão privada ou não, tem-se tornado comum após a implementação do Fundeb, dando a falsa impressão de que a expansão da oferta se efetiva exclusivamente pela rede pública direta. Assim, na Tabela 2 que se segue, subtraímos o número de vagas ofertadas pelo Programa 'Nave-mãe' do total da rede pública.

Tabela 2 - Matrículas na rede direta, 'Naves-mãe', conveniadas e privadas na Educação Infantil em Campinas (2008-2014).

\begin{tabular}{|c|c|c|c|c|c|c|c|}
\hline Oferta & 2008 & 2009 & 2010 & 2011 & 2012 & 2013 & 2014 \\
\hline ** Pública & 25.056 & 22.482 & 24.950 & 24.938 & 23.892 & 23.215 & 22.903 \\
\hline *`Nave-mãe’ & 1.788 & 3.438 & 4.801 & 5.706 & 6.596 & 7.266 & 7.466 \\
\hline *Conveniada & 5.080 & 6.089 & 5.698 & 6.024 & 6.181 & 6.661 & 6.470 \\
\hline **Privada & 8.685 & 7.582 & 6.938 & 7.616 & 9.842 & 9.970 & 11.270 \\
\hline Total EI & 40.609 & 39.591 & 42.387 & 44.284 & 46.511 & $\begin{array}{l}4.112 \\
\end{array}$ & 48.109 \\
\hline
\end{tabular}

Fonte: Organizado pela autora com base nos dados das **Sinopses Estatísticas do Instituto Nacional de Estudos e Pesquisas Educacionais Anísio Teixeira (2008-2014) e *Secretaria Municipal de Educação de Campinas (Núcleo de Educação Infantil e Setor de Convênios).

$\mathrm{Na}$ rede direta houve redução de 2.153 matrículas, enquanto nos CEI de gestão privada ('Naves-mãe) se ampliaram durante toda a série histórica. Em seis anos de vigência do Programa, o acréscimo de matriculados correspondeu a 317,56\%, confirmando o protagonismo do setor privado no atendimento à Educação Infantil. Ao considerar as escolas privadas, historicamente conveniadas com a SME e financiadas com recursos públicos, o "peso" da oferta privada subsidiada aumenta ainda mais. No segmento privado stricto sensu, observamos queda de 12,31\% entre 2008 e 2011, e sua consequente elevação entre 2012 e 2014, correspondendo a 29,76\%. Tal fato pode se vincular ao aumento da renda média do campineiro naquele momento histórico, contribuindo para que as famílias buscassem alternativa no setor privado.

\footnotetext{
${ }^{14}$ Escolas privadas stricto sensu são aquelas que não se enquadram nas categorias inscritas no art. 20 da LDB 9.394/1996, quais sejam: confessionais, filantrópicas ou comunitárias, condição que as coloca regidas pela lógica de mercado (OLIVEIRA, 2007).
} 
Pelos Gráficos 1 e 2, visualizamos a distribuição das matrículas nos anos de 2008 e 2014.

Gráfico 1 - Distribuição das matrículas em Campinas - 2008.

Gráfico 2 - Distribuição das matrículas em Campinas - 2014
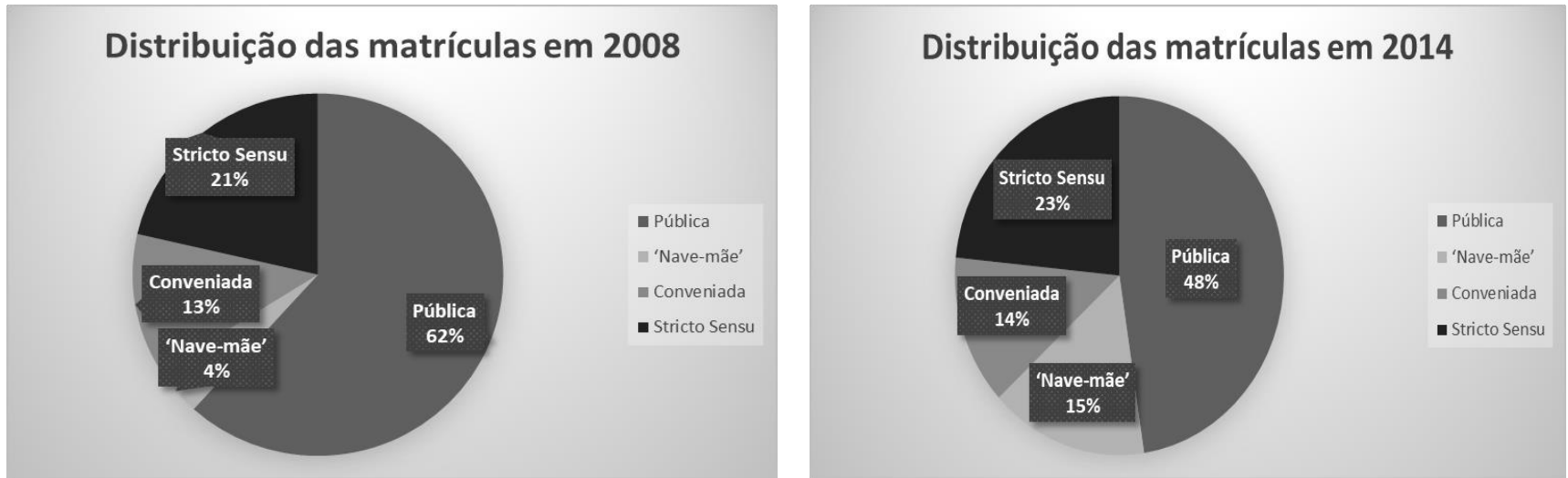

Fonte: Elaborado pela autora com base nos dados das **Sinopses Estatísticas do Instituto Nacional de Estudos e Pesquisas Educacionais Anísio Teixeira (2008-2014) e *Secretaria Municipal de Educação de Campinas (Núcleo de Educação Infantil e Setor de Convênios).

Se no primeiro ano de funcionamento dos CEI 'Naves-mãe' a rede direta foi responsável por $62 \%$ das matrículas na Educação Infantil, em 2014 decaiu 14 pontos percentuais. Já a proporção da oferta via Programa 'Nave-mãe' saltou de 4,4\%, em 2008, para 15\% em 2014. No que se refere à parcela do atendimento pelas conveniadas, observamos poucas alterações ao longo do período, mas não ignoramos que a representatividade da oferta variou entre $13 \%$ e $14 \%$. Além disso, a média da participação das escolas privadas stricto sensu ficou em 20\% entre 2008 e 2014.

O Gráfico 2 mostra claramente que as matrículas públicas não atingiam $50 \%$ da oferta em 2014. Evidencia, ainda, que quase $30 \%$ dos matriculados estavam sob a responsabilidade do setor privado subvencionado e outros $23 \%$ da rede privada lucrativa. Portanto, os dados comprovam o avanço da privatização na oferta da Educação Infantil em Campinas, tendência que se manteve ascendente nos anos posteriores, tal como mostram as informações da Tabela 3, depois da inclusão das matrículas de $2018^{15}$.

Tabela 3 - Matrículas na rede direta, 'Naves-mães', conveniadas e privadas na Educação Infantil em Campinas (2008-2014; 2018).

\begin{tabular}{|c|c|c|c|c|c|c|c|c|}
\hline Oferta & 2008 & 2009 & 2010 & 2011 & 2012 & 2013 & 2014 & 2018 \\
\hline ** Pública & 25.056 & 22.482 & 24.950 & 24.938 & 23.892 & 23.215 & 22.903 & 24.616 \\
\hline *'Nave-mãe’ & 1.788 & 3.438 & 4.801 & 5.706 & 6.596 & 7.266 & 7.466 & 9.943 \\
\hline *Conveniada & 5.080 & 6.089 & 5.698 & 6.024 & 6.181 & 6.661 & 6.470 & 8.383 \\
\hline$* *$ Privada & 8.685 & 7.582 & 6.938 & 7.616 & 9.842 & 9.970 & 11.270 & 13.464 \\
\hline Total EI & 40.609 & 39.591 & 42.387 & 44.284 & 46.511 & 47.112 & 48.109 & 56.406 \\
\hline
\end{tabular}

Fonte: Organizado pela autora com base nos dados das **Sinopses Estatísticas do Instituto Nacional de Estudos e Pesquisas Educacionais Anísio Teixeira (2008-2014) e *Secretaria Municipal de Educação de Campinas (Núcleo de Educação Infantil e Setor de Convênios). Dados de 2018 - Laboratório de Dados Educacionais.

Quatro anos depois da conclusão de nossa pesquisa e onze anos de vigência do Programa mostram que a quantidade de matrículas nas 'Naves-mãe' foi a que mais cresceu, perfazendo um total de

\footnotetext{
${ }^{15}$ No intuito de atualizar as informações e mostrar o comportamento do processo de privatização da Educação Infantil e do Programa 'Nave-mãe' com dados recentes, acessamos o portal do Laboratório de Dados Educacionais, desenvolvido por pesquisadores da Universidade Federal do Paraná, para busca dos dados. O banco é alimentado pela extração das matrículas dos microdados do Censo Escolar do Inep. Para compor as matrículas das 'Naves-mãe', somamos os números de cada CEI 'Nave-mãe' que aparece de forma separada no banco de dados. Disponível em: $<$ https://dadoseducacionais.c3sl.ufpr.br/\#/indicadores/matriculas>. Acesso em: 10 maio 2020.
} 
2.477, entre 2014 e 2018. Em segundo lugar, encontramos as escolas privadas stricto sensu, cujo incremento correspondeu a 2.194 matrículas. Em terceiro, estão as conveniadas, que também ampliaram o atendimento em 1.913 crianças. Da somatória desses três segmentos, alcançamos 31.790 matrículas, 7.174 a mais do total do aumento percebido para a rede pública. Se, em 2014, 53\% da oferta estava sob a responsabilidade do setor privado, em 2018 o percentual passou para 56\%, mostrando que os governantes municipais mantiveram a opção política de ampliar a oferta de vagas via setor privado.

\section{AS ASSOCIAÇÕES PRIVADAS (AP) GESTORAS: PERCEPÇÕES ACERCA DA RELAÇÃO PÚBLICO-PRIVADA}

Os dados de matrículas evidenciaram que, desde o início da vigência do PAEEI, a oferta da Educação Infantil se encontrava em ascensão no segmento privado. Cada CEI 'Nave-mãe' tinha sua gestão transferida para entidades privadas que declaravam em seus estatutos não possuir finalidade lucrativa. Tais instituições se caracterizavam por associações privadas ${ }^{16} \mathrm{de}$ cunho social (DOMICIANOPELLISSON, 2016; DOMICIANO, 2017).

Por estarem assim constituídas, a Legislação Brasileira permite que obtenham vantagens fiscais, ou seja, isenções tributárias sobre o patrimônio, a renda e os serviços relacionados a suas atividades essenciais, desde que não remunerem seus dirigentes (BRASIL, 2002; SZAZI, 2003). Além disso, por se autodeclararem sem fins de lucro, podem acessar recursos públicos. A esse respeito, Oliveira (2007) alerta sobre a fragilidade de considerar apenas esta autodeclaração em seus estatutos, pois, conforme o autor, isso não garante que não visem ou não obtenham lucro.

Dentre as oito associações que geriam os equipamentos públicos em 2014, seis eram de natureza confessional (religiosa) e duas não informaram o segmento ao qual se ligavam; quatro delas indicavam no cadastro da Receita Federal a Educação Infantil ou o apoio à educação como atividade econômica; três aos Direitos Sociais e duas à Assistência Social. Quanto ao ano de origem, duas datavam da década de 1960, duas dos anos de 1980, uma de 1994 e quatro se originaram entre 2000 e 2012 (2000, 2004, 2011 e 2012). No que diz respeito à formalização do convênio para gestão dos equipamentos com a SME, duas o firmaram em 2008, duas em 2009, uma em 2010, duas em 2012 e uma em 2013 (DOMICIANO-PELLISSON, 2016; DOMICIANO, 2017).

Partindo deste cenário geral, apresentamos dois destaques. O primeiro relaciona-se à expressividade de instituições de caráter confessional responsáveis pela gestão desses equipamentos públicos, situação que coloca em discussão o princípio da laicidade assegurado constitucionalmente. Tal preocupação se mostrou relevante e consistente na pesquisa de Silva (2016) quando constatou que, nos CEI por ela investigados, a maioria das docentes contratadas para trabalharem nas 'Naves-mãe' eram evangélicas, pertencentes a diferentes denominações - batista, nazareno, presbiteriana - e em cujas práticas se visualizavam concepções religiosas. A autora também mostrou que a laicidade era uma preocupação frequente na fala das supervisoras da SME, pois práticas de orações diárias com as crianças chegavam constantemente até elas por meio das famílias.

Esse ponto, relacionado às ações pedagógicas no âmbito das 'Naves-mãe', e outros, ligados à área administrativa e financeira, aparecem como fragilidades do controle e acompanhamento do Projeto Político Pedagógico por parte dos profissionais da SME, em relatório de auditoria realizado pela Secretaria Municipal de Gestão e Controle, em junho de $2011^{17}$ :

Nas visitas realizadas nas unidades auditadas, e em contato com as responsáveis das Conveniadas, constatamos grandes deficiências nas questões relacionadas à supervisão administrativa, pedagógica e financeira. Apesar da existência de alguma divergência nos depoimentos colhidos, o sentimento maior é de deficiência marcante nos trabalhos de supervisão. A maior reclamação relaciona-se com ausência de supervisão específica para as

\footnotetext{
${ }^{16}$ O Código Civil brasileiro, lei 10.406, de 10 de janeiro de 2002, define Associação em seu artigo 53 como "a união de pessoas que se organizem para fins não econômicos" (BRASIL, 2002).

${ }^{17}$ Ressaltamos que foram auditados três convênios, praticados de março de 2008 a maio de 2011, com as entidades que concentravam o maior número de CEI 'Naves-mãe' sob suas responsabilidades.
} 
necessidades do projeto Nave-Mãe que se diferencia de outros projetos da rede da SME (CAMPINAS, 2011, p. 29).

As debilidades sinalizadas expõem as dificuldades do acompanhamento sistemático de uma rede educacional tão grande e diversa como a do município de Campinas. Quando pensamos sobre a especificidade ou singularidade do Programa 'Nave-mãe' - contratação de profissionais diretamente pela entidade gestora; carga horária de trabalho que não se iguala à dos servidores da rede pública; salários díspares (MOMMA-BARDELLA; PALMEN; BRYAN, 2014) - essas fragilidades se ampliam (DOMICIANO-PELLISSON, 2016).

Um segundo elemento que destacamos corresponde ao tempo de cadastro das instituições perante a Receita Federal e sua articulação com o processo de conveniamento no município. Os números revelaram que 50\% delas se constituíram entre os anos de 1960 e 1990, permitindo afirmar que se tratava de entidades historicamente presentes na Educação ou na Assistência Social campineira, informação corroborada por Ceccon (2018) e Domiciano-Pellisson (2016). Os outros 50\% originaram-se entre 2000 e 2012, período histórico em que Campinas aprovou e regulamentou duas políticas importantes na área educacional, quais sejam: o repasse de recursos públicos a instituições privadas em $2001^{18}$ (ROCHA, 2009; DOMICIANO-PELLISSON, 2016) e o Programa 'Nave-mãe' em 2007, ambos com aportes de dinheiro público.

Sobre a presença dessas instituições na Educação e/ou Assistência, confirmamos que cinco, das oito instituições que administravam os CEI 'Naves-mãe', tinham convênio na modalidade oferta de vagas anterior à implementação do PAEEI. Se considerarmos ainda que duas passaram a existir depois do Programa, resta apenas uma instituição que não mantinha ligação com a SME. Sabemos que a Experiência na área da Educação era um dos quesitos pontuados na avaliação para seleção das entidades, mas a presença histórica delas na rede reduz a garantia do princípio da impessoalidade, exigido nos processos de seleção pública - uma percepção destacada, também, no relatório de auditoria da Secretaria Municipal de Gestão:

Com base nos exames realizados, verificamos falhas graves no procedimento para seleção de entidades interessadas na gestão de uma Nave-Mãe, como também deficiência no processo formal de escolha da entidade vencedora, em cumprimento aos princípios da moralidade, transparência, isonomia, legalidade, impessoalidade, igualdade, publicidade, probidade administrativa, restando à SME a obrigação de demonstrar cabalmente a vinculação ao instrumento convocatório da Chamada do processo de seleção e o julgamento objetivo (CAMPINAS, 2011, p. 32).

Se a garantia desses princípios é de difícil controle no âmbito da esfera pública com toda a regulação existente, isso se repete na relação que envolve a administração pública e o setor privado.

\section{VALORES DESPENDIDOS PELO GOVERNO MUNICIPAL PARA GESTÃO PRIVADA DOS CEI 'NAVES-MÃE'}

No subitem anterior, ressaltamos que cinco das oito instituições que administravam as 'Naves-mãe' mantinham convênio com a prefeitura na modalidade oferta de vagas para Educação Infantil, gerando sobreposição e captação 'extra' de recursos públicos. Além disso, destacamos que outras duas passaram a existir depois do Programa, e uma se juntou à disputa da gestão dos CEI no decorrer dos anos de vigência.

Uma das opções para captarmos o movimento das disputas pela gestão, que não se desvincula da disputa pelos fundos públicos, foi a observação do número de unidades públicas por Associação Privada (AP) gestora e de matrículas, informações alocadas na Tabela 4.

${ }^{18}$ Lei Municipal no 10.869 , de 29 de junho de 2001. 
Tabela 4 - Movimento da gestão dos CEI 'Nave-mãe' e das matrículas entre as Associações Privadas (AP) - Campinas (2008-2014).

\begin{tabular}{|c|c|c|c|c|c|c|c|c|c|c|c|c|c|c|}
\hline \multirow{3}{*}{ Entidade } & \multicolumn{14}{|c|}{ Número de CEI geridos e de matrículas por entidade } \\
\hline & \multicolumn{2}{|c|}{2008} & \multicolumn{2}{|c|}{2009} & \multicolumn{2}{|c|}{2010} & \multicolumn{2}{|c|}{2011} & \multicolumn{2}{|c|}{2012} & \multicolumn{2}{|c|}{2013} & \multicolumn{2}{|c|}{2014} \\
\hline & CG & MT & CG & MT & CG & MT & CG & MT & CG & MT & CG & MT & CG & MT \\
\hline AP1 & 2 & 923 & 3 & 1.491 & 4 & 1.994 & 4 & 2.115 & 4 & 2.079 & 1 & 552 & 0 & 0 \\
\hline AP2 & 1 & 396 & 2 & 669 & 2 & 854 & 2 & 916 & 2 & 902 & 1 & 518 & 1 & 569 \\
\hline AP3 & 1 & 469 & 1 & 494 & 1 & 461 & 1 & 455 & 1 & 486 & 1 & 516 & 1 & 501 \\
\hline AP4 & - & - & 1 & 428 & 3 & 774 & 5 & 1.371 & 5 & 1.632 & 5 & 1.912 & 5 & 1.910 \\
\hline AP5 & - & - & 1 & 356 & 1 & 430 & 1 & 446 & 1 & 462 & 1 & 498 & 1 & 470 \\
\hline AP6 & - & - & - & - & 1 & 288 & 1 & 403 & 1 & 454 & 1 & 417 & 2 & 1.022 \\
\hline AP7 & - & - & - & - & - & - & - & - & 1 & 225 & 4 & 1.917 & 4 & 1.944 \\
\hline AP8 & - & - & - & - & - & - & - & - & 1 & 356 & 1 & 439 & 1 & 501 \\
\hline AP9 & - & - & - & - & - & - & - & - & - & 0 & 1 & 497 & 1 & 549 \\
\hline Total & 4 & 1.788 & 8 & 3.438 & 12 & 4.801 & 14 & 5.706 & 16 & 6.696 & 16 & 7.266 & 16 & 7.466 \\
\hline
\end{tabular}

Fonte: Sistematizado pela autora com base nos dados disponibilizados pela Secretaria Municipal de Campinas (Núcleo de Educação Infantil).

Legenda: AP - Associação Privada; CG - CEI Gerido; MT - Matrícula.

A Tabela 4 mostra que, até 2012, a gestão e as matrículas se concentravam na AP1 e AP4. Em 2013, tanto a gestão, quanto as matrículas, deslocaram-se da AP1 para AP7, mas se mantiveram na AP4. Sabendo que o subsídio que garante a gestão do CEI é per capita, então, quanto maior o número de CEI gerido, maior o número de matrículas e maior o volume de recursos públicos recebidos.

Observando os valores repassados para gestão das 'Naves', notamos a concentração dos montantes em três entidades privadas, performance que acompanha a ampliação e redução das matrículas ao longo do período.

Tabela 5 - Valores totais repassados pela SME às entidades privadas para gestão dos CEI 'Naves-mãe' - Campinas (2008 a 2014).

\begin{tabular}{c|r|r|r|r|r|r|r}
\hline \multirow{2}{*}{ Instituição } & \multicolumn{7}{|c}{ Valores repassados } \\
\cline { 2 - 8 } & \multicolumn{1}{|c|}{$\mathbf{2 0 0 8}$} & \multicolumn{1}{c}{$\mathbf{2 0 0 9}$} & \multicolumn{1}{c}{$\mathbf{2 0 1 0}$} & \multicolumn{1}{c}{$\mathbf{2 0 1 1}$} & \multicolumn{1}{c}{$\mathbf{2 0 1 2}$} & $\mathbf{2 0 1 3}$ & $\mathbf{2 0 1 4}$ \\
\hline AP1 & $2.436 .869,73$ & $3.843 .097,86$ & $6.390 .321,39$ & $7.136 .927,12$ & $7.428 .872,30$ & $2.474 .058,85$ & \\
AP2 & $1.073 .486,54$ & $2.226 .606,72$ & $2.098 .904,89$ & $2.812 .928,03$ & $3.543 .781,26$ & $2.037 .342,35$ & $2.636 .181,80$ \\
AP3 & $1.190 .788,05$ & $1.614 .396,28$ & $1.507 .572,33$ & $1.630 .961,00$ & $1.771 .601,52$ & $2.053 .139,89$ & $2.517 .906,62$ \\
AP4 & 0,00 & $976.184,95$ & $2.836 .363,17$ & $5.277 .698,23$ & $7.303 .860,84$ & $8.982 .721,74$ & $10.781 .583,22$ \\
AP5 & 0,00 & $599.309,53$ & $1.452 .673,54$ & $1.630 .961,00$ & $1.771 .890,64$ & $2.081 .304,66$ & $2.550 .506,16$ \\
AP6 & 0,00 & 0,00 & $532.323,87$ & $1.245 .025,47$ & $1.697 .489,98$ & $1.881 .998,19$ & $5.274 .852,50$ \\
AP7 & 0,00 & 0,00 & 0,00 & 0,00 & $865.586,64$ & $7.992 .946,55$ & $9.407 .648,64$ \\
AP8 & 0,00 & 0,00 & 0,00 & 0,00 & $1.185 .530,40$ & $2.132 .217,92$ & $2.620 .595,16$ \\
AP9 & 0,00 & 0,00 & 0,00 & 0,00 & 0,00 & $2.135 .106,61$ & $2.871 .917,20$ \\
\hline Total & $4.701 .144,31$ & $\mathbf{9 . 2 5 9 . 5 9 5 , 3 5}$ & $\mathbf{1 4 . 8 1 8 . 1 5 9 , 1 7}$ & $\mathbf{1 9 . 7 3 4 . 5 0 0 , 8 6}$ & $\mathbf{2 5 . 5 6 8 . 6 1 3 , 5 8}$ & $\mathbf{3 1 . 7 7 0 . 8 3 6 , 7 6}$ & $\mathbf{3 8 . 6 6 1 . 1 9 1 , 2 9}$ \\
\hline
\end{tabular}

Fonte: Sistematizado pela Autora com base em: CAMPINAS. Relatório de repasses de recursos às instituições privadas que gerem os CEI 'Naves-mãe' (2008-2014) - Administração e Gerenciamento de Convênios-SME.

OBS. Valores em reais indexados para o mês de dezembro de 2019, pelo Índice Nacional de Preços do Consumidor do Instituto Brasileiro de Geografia e Estatística.

A análise dos valores repassados às entidades privadas entre 2008 e 2014 complementa os dados da tabela anterior (Tabela 4). Verificamos que, quanto maior o número de CEI e de matrículas, maior a captação de recursos públicos. Sendo assim, o volume de dinheiro recebido pela AP1 triplicou no terceiro ano de convênio com a prefeitura, mantendo-se até seu respectivo encerramento. 
No decorrer do período, a AP4, AP6 e AP7 ampliaram o número de CEI 'Naves-mãe' sob suas responsabilidades e, consequentemente, os valores recebidos. Tal acréscimo correspondeu, respectivamente, a $890,91 \%, 1.004,47 \%$ e $986,86 \%{ }^{19}$.

Para aquelas que mantiveram a quantidade de unidades ao longo do Programa, os repasses aumentaram por dois motivos: o acréscimo de matrículas e do valor per capita (DOMICIANOPELLISSON, 2016). Os recursos carreados à AP3, por exemplo, subiram 111,45\% de 2008 a 2014 , enquanto as matrículas se ampliaram 7,47\%; já na AP5, o valor subiu 325,58\% de 2009 a 2013 e, as matrículas, 32\%; na AP8, em três anos de convênio, o montante aumentou 121,05\% e, as matrículas, $40 \%$. Por fim, à AP9 transferiram-se 34,51\% de recursos a mais de um ano para outro, enquanto as matrículas cresceram 10\%. Assim, percebemos que o percentual de dinheiro repassado extrapola o da ampliação de matrículas em todas as entidades privadas.

Tabela 6 - Proporção da apropriação dos recursos públicos repassados às entidades privadas Campinas (2008-2014).

\begin{tabular}{c|c|r}
\hline CEI & \% & \multicolumn{1}{|c}{$\begin{array}{c}\text { Total repassado } \\
(\mathbf{2 0 0 8 - 2 0 1 4 )}\end{array}$} \\
\hline AP1 & 20,56 & $29.710 .147,26$ \\
AP2 & 11,37 & $16.429 .231,59$ \\
AP3 & 8,50 & $12.286 .365,68$ \\
AP4 & 25,02 & $36.158 .412,14$ \\
AP5 & 6,97 & $10.086 .645,53$ \\
AP6 & 7,35 & $10.631 .690,01$ \\
AP7 & 12,63 & $18.266 .181,83$ \\
AP8 & 4,10 & $5.938 .343,48$ \\
AP9 & 3,46 & $5.007 .023,80$ \\
\hline Total & $\mathbf{1 0 0}$ & $\mathbf{1 4 4 . 5 1 4 . 0 4 1 , 3 2}$ \\
\hline
\end{tabular}

Fonte: Sistematizado pela autora com base em: CAMPINAS. Relatório de repasses de recursos às instituições privadas que gerem os CEI 'Naves-mães' (2008-2014) - Administração e Gerenciamento de Convênios-SME.

OBS. Valores em reais indexados para o mês de dezembro de 2019, pelo Índice Nacional de Preços do Consumidor do Instituto Brasileiro de Geografia e Estatística.

Relacionando os dados das Tabelas 5 e 6, destacamos que a concentração e a ampliação de recursos públicos nas associações AP1, AP4 e AP7, correlacionadas ao número de CEI gerido, de matrículas e ao formato de repasse per capita, tendem a estimular e incentivar a disputa pela administração das unidades públicas.

\section{CONSIDERAÇÕES FINAIS}

Conforme apresentado, a partir da lei 12.884/2007, o governo municipal de Campinas-SP ficou autorizado a construir equipamentos de Educação Infantil públicos e transferir a gestão para instituições privadas com repasse de recursos públicos. O PAEEI, popularizado como Programa 'Navemãe', inaugurou uma forma alternativa de executar a política educacional no município, algo que não se visualizava no interior paulista.

Com capacidade para atender até 500 crianças de 0 a 5 anos em um único equipamento, o Programa 'Nave-mãe' ampliou o atendimento na Educação Infantil. Domiciano-Pellisson (2016) evidenciou que a taxa de matrícula líquida na creche em 2007 era de 19,88\%, subindo para 37,90\% no ano de 2014, ampliação correspondente a 18 pontos percentuais. Na pré-escola, a taxa de matrícula líquida em 2008 - 110\% - já sinalizava sua universalização, não justificando, assim, o atendimento pela via privada.

\footnotetext{
${ }^{19}$ No ano de 2015, a AP4 ganhou quatro editais de processo seletivo público, totalizando nove CEI sob sua administração. Os recursos adicionais transferidos a esta entidade corresponderam a R\$4.138.939,73. A AP6 também agregou três novos CEI 'Naves-mãe' à sua gestão, um inaugurado em julho de 2015 e outros três entregues ao longo do mesmo ano. A quantia prevista no Termo de Convênio para gestão do CEI era de R\$1.358.069,30 (DOMICIANO-PELLISSON, 2016).
} 
Considerando esta contradição, ainda que reconheçamos a ampliação do acesso, o movimento das matrículas ao longo do período analisado (2008-2014) evidenciou que, a partir da vigência do Programa em 2008, se tornou ascendente no segmento privado. Tal dado explicita que o atendimento pela rede direta foi se secundarizando e que a opção política por ampliar a Educação Infantil via setor privado se sobrepôs. Essa situação foi iniciada na gestão de Dr. Hélio, e aprofundada e continuada por seus sucessores (CECCON, 2018).

De acordo com pesquisa anterior (DOMICIANO-PELLISSON, 2016), a intenção política em consolidar uma rede de atendimento indireto na Educação Infantil antecedeu a formalização do PAEEI. Pelos Planos Plurianuais (PPA), elaborados para os quadriênios de 2006-2009 e 2010-2013, encontramos evidências explícitas acerca da prioridade orçamentária sobre a rubrica relacionada à construção dos CEI 'Naves-mãe', concretizada a partir de 2007, quando as construções se iniciam.

Por esses dados, constatamos que o Programa se consolidou como uma rede indireta de unidades de Educação Infantil, à semelhança do município de São Paulo (FRANCO, 2015). Consoante a Franco (2015), Domiciano-Pellisson (2016) e Franco et al. (2019), os CEI indiretos são equipamentos construídos, equipados e mantidos com fundos públicos, mas de gestão privada. Nas experiências estudadas pelos respectivos autores, as diferenciações no padrão de atendimento entre os CEI diretos e indiretos aparecem como um ponto em comum.

O modelo de privatização via PAEEI, além de ser sustentado com recursos públicos - os quais defendemos ser prioritários e/ou exclusivos para investimento na rede direta -, deslocou a elaboração e execução do Projeto Político Pedagógico para o setor privado, e suas consequências merecem aprofundamento; transferiu a contratação dos profissionais envolvidos nas atividades meio e atividades fim às entidades privadas; entregou a educação da criança menor de 6 anos a este segmento, relegando-a aos interesses de grupos privados; atestou a desigualdade no atendimento aos pequenos em uma mesma rede de atendimento, confirmando estudos anteriores de Momma-Bardella, Palmen e Bryan (2014). Neste processo, a SME passou a cumprir papel meramente fiscalizador e regulador da oferta educacional campineira.

A sobreposição dos convênios surgiu também como um dado importante nesta complexa relação público-privada. Com aval da legislação brasileira, que constantemente reedita ou renova a permissão de repasse de recursos públicos ao setor privado, assistimos com o PAEEI a destinação de R\$144.514.041,32 para as Associações que geriam os CEI 'Naves-mãe' entre 2008 e 2014. Deste total, três instituições juntas acessaram mais de $50 \%$ dos recursos: por um lado, por terem o maior número de crianças nos equipamentos geridos e, por outro, por concentrarem o maior número de unidades sob suas responsabilidades.

Insistimos em estabelecer a relação entre subsídio per capita, número de matrículas e interesse na disputa pela gestão. Concordamos com Campos (1989) que as vantagens financeiras são motivadoras para participação das entidades nos processos seletivos públicos, contribuindo para perpetuar e cristalizar tais instituições na estrutura do sistema e na política educacional local.

Ainda destacamos que, além do gasto com o per capita para gestão, o executivo municipal forneceu a merenda, kits de material escolar e custeou a construção dos equipamentos educacionais 'Naves-mãe', ampliando, assim, o volume de fundos públicos destinados ao setor privado.

A opção do executivo municipal em utilizar recursos públicos para custear a construção dos equipamentos do PAEEI indica, também, a busca pelo "barateamento" do custo de manutenção. Para Carreira e Pinto (2007), os gastos com construção se inscrevem nos custos de implantação (aquisição de terreno, construção do prédio, compra de equipamento e material permanente), incorporando-se uma única vez pela administração pública no orçamento; isso significa dizer que estes investimentos "pesarão" apenas uma vez na conta do município. Assim, transferir a gestão das unidades construídas para o setor privado significa reduzir o custo de manutenção da escola, cuja exigência de aportes de recursos é maior e de natureza contínua.

Por fim, o Programa 'Nave-mãe' materializa a orientação de transferência da gestão do equipamento público para o setor privado, na perspectiva da lógica gerencialista defendida pelos setores hegemônicos com vistas à "flexibilização" da gestão pública, confirmando tendências anunciadas por Adrião e Bezerra (2013). 
Entretanto, ao contrário da eficiência privada pressuposta e idealizada pelos reformistas gerencialistas, afirmamos que as articulações público-privadas explicitam ou escancaram problemas circunscritos a essas relações, tais como: dificuldades no controle social, falta de transparência no uso dos recursos públicos, favorecimento do capital em detrimento dos direitos sociais e históricas relações clientelistas (CARVALHO, 1997), desfavorecendo o cumprimento do direito humano educacional.

Para efetivação do direito humano à educação, reafirmamos posição já publicizada em outros artigos e documentos que tomam os estudos de Tomasevski (2003), Ximenes (2014) e Adrião et al. (2016) como base. Ao sinalizarmos que Campinas ampliou vagas na Educação Infantil sob a égide do setor privado, asseveramos que, quanto ao direito humano à educação, a garantia à vaga é uma das dimensões do acesso, mas não a única, somando-se a ela outras quatro: 1) disponibilidade, que significa oportunidades educacionais em número suficiente; 2 ) acessibilidade, que compreende garantia de acesso a todos e todas sem discriminação - englobando, portanto, acessibilidade física, econômica e social; 3) aceitabilidade, que consiste em garantir educação socialmente aceitável, com respeito aos direitos humanos e aos propósitos públicos - cidadania, redução das desigualdades, bem como sustentabilidade socioambiental; e, por fim, 4) adaptabilidade, que requer a garantia da gestão democrática da educação com a participação de todos os entes federados e população, de propostas político-pedagógicas que respeitem os direitos fundamentais das crianças, jovens e adultos. Por isso, destacamos a importância do fortalecimento das pesquisas sobre privatização e da defesa na manutenção da educação sob a gestão, o financiamento e a oferta pública.

\section{REFERÊNCIAS}

1. ADRIÃO, T. Indicações e reflexões sobre as relações entre esferas públicas e privadas para a oferta educacional no Brasil. Políticas Educativas. Porto Alegre, v. 3, n. 1, p. 48-64, 2009.

2. ADRIÃO, T. M. F.; PERONI, V. (Coord.). Gestão Municipal da Educação e as parcerias com o Instituto Ayrton Senna. Goiânia: FUNAP; RECIFE: ANPAE, 2013.

3. ADRIÃO, T.; BEZERRA, E. P. O setor não lucrativo na gestão da educação pública: corresponsabilidade ou debilidade. Currículo sem Fronteiras, v. 13, n. 2, p. 256-268, maio-ago., 2013.

4. ADRIÂO, T. Escolas Charters nos EUA: contradições de uma tendência proposta para o Brasil e suas implicações para a oferta da educação básica. Educação e Filosofia, Uberlândia, v. 28, n. especial, p. 263-282, 2014.

5. ADRIÃO, T. et al. Grupos empresariais na educação: limites à efetivação do direito à educação. Educação \& Sociedade, v. 37, n. 134, p. 113-131, jan.-mar., 2016.

6. ADRIÃO, T. Dimensões e formas da privatização da educação no Brasil: caracterização a partir de mapeamento de produções nacionais e internacionais. Currículo sem Fronteiras, v. 18, n. 1, p. 8-28, jan.-abr., 2018.

7. BAUER, A. Do direito à educação à noção de quase-mercado: tensões na política de educação básica brasileira. RBPAE, v. 24, n. 3, p. 557-575, set.- dez., 2008.

8. BELFIELD, C. R.; LEVIN, H. M. Education privatization: causes, consequences and planning implications. United Nations Educational, Scientific and Cultural Organization, Paris. Fundamentals of Educational Planning, n. 74, 2002.

9. BRASIL. Lei no 8.069, de 13 de junho de 1990. Dispõe sobre o Estatuto da Criança e do Adolescente e dá outras providências. Diário Oficial da União, Brasília, 1990. Disponível em: http://www.planalto.gov.br/ccivil_03/leis/18069.htm. Acesso em: 25 jun. 2020.

10. BRASIL. Lei no 9.394, de 20 de dezembro de 1996. Estabelece as Diretrizes e Bases da Educação Nacional. Diário Oficial da União, Brasília, 1996. Disponível em: http://www.planalto.gov.br/ccivil_03/leis/19394.htm. Acesso em: 25 jun. 2020.

11. BRASIL. Emenda Constitucional no 19, de 19de abril de 1998. Modifica o regime e dispõe sore princípio e normas da Administração Pública, servidores e agentes políticos, controle de despesas e finanças públicas e custeio de atividades a cargo do Distrito Federal, e dá outras providências. Diário Oficial da União, Brasília, 1998. Disponível em: 
http://www.planalto.gov.br/ccivil_03/constituicao/Emendas/Emc/emc19.htm. Acesso em: 13 maio 2007.

12. BRASIL. Lei $\mathrm{n}^{\circ} 10.406$, de 10 de janeiro de 2002. Institui o novo Código Civil. Diário Oficial da União, Brasília, 2002. Disponível em: http://www.planalto.gov.br/ccivil_03/leis/2002/110406.htm. Acesso em: 25 jun. 2020.

13. BRASIL. Lei no 11.494, de 20 de junho de 2007. Regulamenta o Fundo de Manutenção e Desenvolvimento da Educação Básica e de Valorização dos Profissionais da Educação FUNDEB, de que trata o art. 60 do Ato das Disposições Constitucionais Transitórias; altera a Lei n o 10.195, de 14 de fevereiro de 2001; revoga dispositivos das Leis n os 9.424, de 24 de dezembro de 1996, 10.880, de 9 de junho de 2004, e 10.845, de 5 de março de 2004; e dá outras providências. Diário Oficial da União, Brasília, 2007. Disponível em: http://www.planalto.gov.br/ccivil_03/_ato2007-2010/2007/lei/111494.htm. Acesso em: 25 jun. 2020.

14. BRASIL. Lei no 13.005 , de 25 de junho de 2014. Aprova o Plano Nacional de Educação e dá outras providências. Diário Oficial da União, Brasília, 2014. Disponível em: https://www2.camara.leg.br/legin/fed/lei/2014/lei-13005-25-junho-2014-778970publicacaooriginal-144468-pl.html. Acesso em: 25 jun. 2020.

15. CAMPINAS. Decreto $n^{\circ} 11.051$, de 23 de dezembro de 1992. Dispõe sobre o reagrupamento de unidades sócio-educacionais da Secretaria Municipal de Educação e dá outras providências. Diário Oficial do Município, Campinas, 1992. Disponível em: http://bibjuri.campinas.sp.gov.br/index/visualizaratualizada/id/89809. Acesso em: 25 jun. 2020.

16. CAMPINAS. Lei no 10.869, de 29 de junho de 2001. Dispõe sobre o repasse de recursos orçamentários da secretaria municipal de educação às entidades, instituições e grupos comunitários legalmente constituídos. Diário Oficial do Município. Diário Oficial do Município, Campinas, 2001. Disponível em: http://www.campinas.sp.gov.br/bibjuri/lei10869.htm. Acesso em: 25 jun. 2020.

17. CAMPINAS. Projeto de Lei $\mathbf{n}^{\mathbf{0}} \mathbf{1 3 3}$, de 12 de março de 2007. Dispõe sobre a criação do Programa de Atendimento Especial à Educação Infantil (PAEEI).

18. CAMPINAS. Lei $\mathbf{n}^{\mathbf{0}} \mathbf{1 2 . 8 8 4}$, de 04/04/2007a. Dispõe sobre a criação do Programa de Atendimento Especial à Educação Infantil - PAEEI.

19. CAMPINAS. Relatório de Auditoria Convênio das Naves-mães. Campinas: Secretaria de Gestão e Controle, Departamento de Auditoria, 2011. 34 p. Disponível em: http://www.campinas.sp.gov.br/governo/gestao-econtrole/relatorio_auditoria_naves_mae.pdf. Acesso em: 15 mar. 2013.

20. CAMPINAS. Decreto $\mathbf{n}^{\mathbf{0}} \mathbf{1 7 . 5 2 3}$, de 27 de fevereiro de 2012. Altera o Decreto Municipal $\mathbf{n}^{\circ}$ 15.947, de 17 de agosto de 2007, que regulamenta a lei 12.884, de 04 de abril de 2007, que cria o Programa de Atendimento Especial à Educação Infantil - PAEEI.

21. CAMPINAS. Guia Gestor, 2013 (mimeo).

22. CAMPINAS. Decreto $\mathbf{n}^{\mathbf{0}} \mathbf{1 7 . 9 5 1}$, de 2 de maio de 2013. Dispõe sobre a denominação das escolas municipais de Educação Infantil. Disponível em: https://bibliotecajuridica.campinas.sp.gov.br/index/visualizaroriginal/id/92759. Acesso em: 25 jun. 2020.

23. CAMPINAS. Decreto n. 18.664, de 03 de março de 2015. Dispõe sobre a denominação das Escolas Municipais de Educação Infantil. Disponível em: https://bibliotecajuridica.campinas.sp.gov.br/index/visualizaroriginal/id/128208. Acesso em: 27 mai. 2020.

24. CAMPOS, M. M. Pré-escola: entre a educação e o assistencialismo. Cadernos de Pesquisa. São Paulo, n. 53, mai., 1985. Disponível em: http://publicacoes.fcc.org.br/ojs/index.php/cp/article/view/1374/1374. Acesso em 04 set. 2020.

25. CARREIRA, D.; PINTO, J. M. R. Custo Aluno-Qualidade inicial: rumo à educação pública de qualidade no Brasil. São Paulo: Global, 2007. 
26. CARVALHO, J. M. Mandonismo, Coronelismo, Clientelismo: uma discussão conceitual. Dados. Rio de Janeiro, v. 40, n. 2, 1997.

27. CECCON, M. L. L. Instituições sem fins lucrativos na educação infantil, no município de Campinas: histórico, dilemas e perspectivas. 2018. Dissertação (Mestrado em Educação) Faculdade de Educação, Universidade Estadual de Campinas, Campinas, 2018.

28. CORREA, B. C. A educação Infantil. In: OLIVEIRA, R. P.; ADRIÃO, T. (Org.). Organização do Ensino no Brasil: níveis e modalidades na Constituição Federal e na LDB. 2. ed. São Paulo: Xamã, 2007.

29. DOMICIANO, C. A. O Programa 'Bolsa Creche' nos municípios paulistas de Piracicaba e Hortolândia: Uma proposta para alocação de recursos estatais à educação privada? $228 \mathrm{f}$. Dissertação (Mestrado em educação) - Instituto de Biociências de Rio Claro, Universidade Estadual Paulista, Rio Claro, 2009.

30. DOMICIANO, C. A. O Projeto 'Nave-mãe' no município paulista de Campinas e os Objetivos para o Desenvolvimento do Milênio: tendências de privatização da educação infantil. Revista Políticas Educativas. Porto Alegre, v. 6, n. 1, 2012, p. 90-106.

31. DOMICIANO-PELLISSON, C.A. A cogestão dos Centros de Educação Infantil 'Navemãe': uma parceria púlico-privada analisada. Tese de Doutorado. Faculdade de Educação. Universidade Estadual de Campinas, Campinas, 2016.

32. DOMICIANO, C. A. O setor privado na administração de unidades de educação infantil públicas no município paulista de Campinas: conhecendo seus atores. International Studies on Law and Education. CEMOrOC-Feusp/IJI-Univ. Do Porto. n. 27, set.-dez, 2017.

33. ENTENDA a sucessão de fatos que levaram à cassação de dr. Hélio. Folha de São Paulo, São Paulo, 20 ago. 2011. Poder. Disponível em: https://www1.folha.uol.com.br/poder/962884entenda-a-sucessao-de-fatos-que-levaram-a-cassacao-de-dr-helio.shtml. Acesso em: 13 ago. 2014.

34. FARIA, Ana Lúcia Goulart de. A contribuição dos parques infantis de Mário de Andrade para a construção de uma pedagogia da educação infantil. Educação e Sociedade. Campinas, n. 69, p. 60-91, dez. 1999.

35. FARIA, Ana Lúcia Goulart de. Políticas de regulação, pesquisa e pedagogia na educação infantil, primeira etapa da educação básica. Educação e Sociedade. Campinas, vol. 26, n. 92, p. 10131038, out. 2005.

36. FILGUEIRAS, C. A. C. A creche comunitária na nebulosa da pobreza. Cadernos de Pesquisa. São Paulo, n. 88, p. 18-29, fev. 1994.

37. FRANCO, D. S. As creches na educação paulistana (2002-2012). 2015. Tese (Doutorado em Educação) - Faculdade de Educação, Universidade Estadual de Campinas, Campinas, 2015.

38. GARCIA, T.; ADRIÃO, T.; BORGHI, R. A Nova Gestão Pública e o contexto brasileiro. In: MARTINS, Â. M. (Org.). Instituições educacionais: políticas, gestão e práticas profissionais. Santos: Editora Universitária Leopoldianum, 2009. p. 13-26.

39. GIDDENS, A. Sociologia. Porto Alegre: Artmed, 2005.

40. GODOY, A. S. Pesquisa Qualitativa: Tipos Fundamentais. Revista de Administração de Empresas. São Paulo, vol. 35, n. 3, maio-jun. 1995, p. 20-29.

41. GOMIDE, D. C.; JACOMELI, M. R. M. O método de Marx na pesquisa sobre políticas educacionais. Políticas Educativas, Santa Maria, v. 10, n. 1, p. 64-78, 2016.

42. HARVEY, D. O novo imperialismo. 2. ed. São Paulo: Edições Loyola, 2005.

43. HARVEY, D. Condição pós-moderna. 18 ed. São Paulo: Edições Loyola, 2009.

44. HOBSBAWN, E. Era dos extremos: o breve século XX: 1914-1991. São Paulo: Companhia das Letras, 1995.

45. INSTITUTO NACIONAL DE ESTUDOS EDUCACIONAIS ANÍSIO TEIXEIRA. Sinopses Estatísticas da Educação Básica (2008-2014). Brasília, 2008, 2009, 2010, 2011, 2012, 2013, 2014. Disponível em: http://portal.inep.gov.br/web/guest/sinopses-estatisticas-daeducacao-basica. Acesso em: 13 ago. 2015.

46. JUNQUILHO, G. S. Reforma gerencial o "gerente caboclo" frente os desafios da reforma do Estado no Brasil. In: CONGRESO INTERNACIONAL DEL CLAD SOBRE LA 
REFORMA DEL ESTADO Y DE LA ADMINISTRACIÓN PÚBLICA, 7., 2002, Lisboa. Anais [...]. Lisboa, Portugal, 2002, p. 1-23.

47. JUNQUILHO, G. S. Nem "burocrata" nem "novo gerente": o "caboclo" e os desafios do Plano Diretor de Reforma do Estado no Brasil do real. Revista de Administração Pública. Rio de Janeiro, v. 38, n. 1, p. 137-156, jan.-fev., 2004.

48. KRAMER, S. A política do pré-escolar no Brasil: a arte do disfarce. 5. ed. São Paulo: Cortez, 1995.

49. KUHLMANN Jr., M. Histórias da educação infantil brasileira. Revista Brasileira de Educação. São Paulo, n. 14, p. 5-18, maio-ago., 2000.

50. KUHLMANN Jr., M. Infância e educação infantil: uma abordagem histórica. 3. ed. Porto Alegre: Mediação, 2004.

51. LABORATÓRIO DE DADOS EDUCACIONAIS. Disponível em: https://dadoseducacionais.c3sl.ufpr.br/\#/indicadores/matriculas. Acesso em: 20 maio 2020.

52. MINISTRO da educação reafirma que há plantações de maconha nas universidades. Câmara dos deputados. Educação, cultura e esportes, Brasília, 11 de dezembro de 2019. Disponível em: https://www.camara.leg.br/noticias/625418-ministro-da-educacao-reafirma-que-haplantacoes-de-maconha-nas-universidades/. Acesso em: 14 dez. 2019.

53. MOMMA-BARDELA, A. M.; PALMEN, S. H. C.; BRYAN, N. A. P. Políticas públicas de educação infantil em Campinas: tessituras sobre a coexistência de diferentes e diversas formas de organização. Revista Exitus, Santarém, v. 4, n. 1, p. 33-57, 2014.

54. OLIVEIRA, J. S.; BORGHI, R. F. Arranjos institucionais entre o poder público municipal e instituições privadas para oferta de vagas na educação infantil. Rev. Bras. Estud. Pedagog. Brasília,v. 94, n. 236, p. 150-167, Apr. 2013. Disponível em: $<$ http://www.scielo.br/scielo.php?script=sci_arttext\&pid=S217666812013000100008\&lng=en\&nrm=iso $>$. Acesso em 04 Set. 2020.

55. OLIVEIRA, R. P. O financiamento da educação. In: OLIVEIRA, R. P.; ADRIÃO, T. (Org.). Gestão, financiamento e direito à educação: Análise da LDB e da Constituição Federal. 3. ed. São Paulo: Xamã, 2007.

56. PEREIRA, L. C. B. Gestão do setor público: estratégia e estrutura para um novo Estado. In: PEREIRA, B.; SPINK, P. (Org.). Reforma do Estado e Administração Pública Gerencial. Rio de Janeiro: Fundação Getúlio Vargas, 1998. p. 21-38.

57. PERONI, V.; ADRIÃO, T. Público não-estatal: estratégias para o setor educacional brasileiro. In: ADRIÃO, T.; PERONI, V. (Org.). O Público e o privado na educação: interfaces entre o Estado e Sociedade. São Paulo: Xamã, 2005. p. 138-153.

58. PERONI, V. M. V.; OLIVEIRA, R. T. C.; FERNANDES, M. D. E. Estado e terceiro setor: as novas regulações entre o público e o privado na gestão da educação básica brasileira. Educação e Sociedade. Campinas: v. 30, n. 108, p. 761-778, out. 2009.

59. PERONI, V. (Org.). Redefinições das fronteiras entre o público e o privado: implicações para a democratização da educação. Brasília: Liber Livro, 2013.

60. PINTO, J. M. R. A política recente de fundos para o financiamento da educação e seus efeitos no pacto federativo. Revista Educação e Sociedade. Campinas, v. 28, n. 100, p. 877-897, 2007. Disponível em: https://www.scielo.br/scielo.php?script=sci_arttext\&pid=S0101 73302007000300012. Acesso em: 25 jun. 2020.

61. ROCHA, A. C. As ações da prefeitura municipal de Campinas frente à demanda por vagas na educação infantil (2001 a 2008). 2009. Dissertação (Mestrado em Educação) Centro de Educação e Ciências Humanas, Universidade Federal de São Carlos, São Carlos, 2009.

62. ROSEMBERG, F. Expansão da educação infantil e processos de exclusão. Cadernos de Pesquisa. n. 107, p. 7-40, 1999. Disponível em: https://www.scielo.br/pdf/cp/n107/n107a01.pdf. Acesso em: 25 jun. 2020.

63. ROSEMBERG, F. Para uma outra educação infantil paulistana pós FUNDEB. [Palestra] I ENCONTRO DE EDUCAÇÃO PARA UMA OUTRA SÃO PAULO. 2007 Disponível em: 
https://www.nossasaopaulo.org.br/portal/files/EducacaoInfantil2.pdf. Acesso em: 27 maio 2020.

64. SANT'ANA, J. Painel das privatizações: as estatais que o governo quer vender, e as que estão escapando. Gazeta do Povo, Curitiba, 10 de setembro de 2019. Disponível em:

https://especiais.gazetadopovo.com.br/politica/painel-das-privatizacoes/. Acesso em: 14 dez. 2019.

65. SANTOS, H. O. Naves-mãe e a pedagogia dos sentidos; de Campinas novos paradigmas para educação infantil no Brasil. Campinas: Komedi, 2010.

66. SILVA, N. A. Educação Infantil e as relações público-privado no município de Campinas: o Programa Nave-mãe. 2016. Dissertação (Mestrado em Educação) - Faculdade de Educação, Universidade Estadual Paulista de Campinas, Campinas, 2016.

67. SISTEMA ESTADUAL DE ANÁLISE DE DADOS (SEADE). 2014. Disponível em: http://www.seade.gov.br/produtos/projpop/index.php?pes=3. Acesso em: 13 jan. 2013.

68. SZAZI, E. Terceiro Setor: Regulação no Brasil. 3. ed. São Paulo: Pieirópolis, 2003.

69. TOMASEVSKI, K. Contenido y vigencia del derecho a la educación. San José: Instituto Interamericano de Derechos Humanos, 2003.

70. XIMENES, S. B. Padrão de qualidade do ensino: desafios institucionais e bases para a construção de uma teoria jurídica. 2014. Tese (Doutorado em Direito do Estado) Universidade de São Paulo, São Paulo, 2014.

Submetido: $14 / 12 / 2019$

Aprovado: $12 / 06 / 2020$ 